\title{
EVALUACIÓN SENSORIAL DE ACEITUNAS NEGRAS FERMENTADAS CON Y SIN ACETIFICACIÓN DE LA SALMUERAS
}

Responsable : Msc. Marcial Alfredo Castillo Cohaila

\section{RESUMEN}

Las aceitunas negras fueron sometidas a proceso de fermentación. con dos tratamientos: uno con acetificación y otro sin acetificación de la salmuera inicial; con tiempos de fermentación en ambos tratamientos de 90 dias.

La acetificación de la salmuera inicial para el tratamiento con acetificación, se realizó hasta alcanzar un $\mathrm{pH}$ de 3,8.

El análisis sensorial se realizó para el color, olor, sabor, textura y aspecto general de las aceitunas negras fermentadas, evaluándose el efecto que tiene la presencia del ácido acético en la calidad sensorial de la aceitunas fermentadas, desde un punto de vista del consumidor, teniendo como referencia las aceitunas fermentadas sin acetificación de la salmuera.

\section{ABSTRACT}

The black olives, were put under fermentation process, with two treatments; one with addition of acetic acid and another one without addition of acetic acid in the initial brine; with times of fermentation in both treatments of 90 days.

The addition of acetic acid in the initial brine for the treatment with addition of acetic acid, was made until reaching $\mathrm{pH}$ of 3,8 .

The sensorial analysis, was made for the color, scent, flavor, texture and general aspect of the fermented black olives: evaluating the effect that has the presence of acetic acid in the sensorial quality of the olives fermented, from a point of view of the consumer, having as reference the olives fermented without addition of acetic acid in the brine.

\section{INTRODUCCIÓN}

La utilización de los aditivos en los alimentos ha permitido el desarrollo de la tecnología de los alimentos, siendo asi que en el caso de las aceitunas negras fermentadas, esta realidad no es diferente.

Uno de los productos muy utilizados en el proceso fermentativo de las aceitunas negras lo constituye el ácido acético, producto que se utiliza según las conveniencias de preparación de cada productor de aceituna de mesa, cuyo uso, para la acetificación de las salmueras, según norma CODEX, se establece conforme las buenas prácticas de manufactura.

En el pais, la tradición mantiene la tendencia hacia el consumo de las aceitunas negras, seguramente por su gusto tan particular. Por ello, con el presente trabajo se buscó establecer si este gusto particular es motivado por el tratamiento acetificante que normalmente se da a las aceitunas 0 es caracteristico de la variedad de aceituna utilizada. La acetificación de las salmueras de fermentación de las aceitunas se realiza comúnmente para prevenir alteraciones indeseables en las fermentaciones. Las cantidades de uso son variables, siendo común el uso de 1 litro de ácido acético glacial para 1000 litros de salmuera.

El análisis sensorial es la disciplina que obtiene, mide, analiza e interpreta las reacciones del ser humano al percibir mediante sus sentidos las caracteristicas de los alimentos. La calidad sensorial de las aceitunas de mesa viene determinada por una serie de caracteristicas clasificadas por los órganos sensoriales, constituyendo, el color y el sabor los principales atributos que contribuyen a la aceptación por parte del consumidor.

Realmente no existe un método normalizado para valorar las propiedades sensoriales de las aceitunas de mesa. Se utilizan varios métodos y se pueden hacer varias interpretaciones. La falta de homogeneidad y estandarización en las pruebas provoca confusión y dificultades para comparar resultados.

\section{OBJETIVOS}

Los objetivos del trabajo de investigación fueron los siguientes:

\section{1) Objetivo Principal}

Determinar el efecto que tiene la acetificación inicial de las salmueras en la calidad sensorial de las aceitunas negras fermentadas.

\section{2) Objetivo Especifico}

Determinar el (o los) atributo sensorial que confiere diferencia sensorial a las aceitunas fermentadas.

\section{MATERIAL Y METODOS}

El trabajo de investigación se desarrolló en los ambientes de la Facultad de Ingenieria en Industrias Alimentarias. 


\section{1) Recursos Materiales}

Los recursos materiales utilizados fueron: 40 kilogramos de aceitunas negras, 02 depósitos plásticos de 30 litros c/u para la fermentación de las aceitunas, sal, ácido acético y agua potable.

El material de laboratorio utilizado fue: densimetro Baumé, probeta, pipetas, balanza analitica, pH-metro, etc.

\section{2) Panelistas}

Los panelistas o jueces para la realización de la evaluación sensorial fueron en total 8 , los cuales previamente fueron instruidos en las caracteristicas de calidad de las aceitunas negras fermentadas al natural, con y sin acetificación.

\section{3) Formato de Evaluación Sensorial}

Los panelistas contaron con una hoja de evaluación que permite evaluar si existe diferencia entre las aceitunas tratadas con ácidos acético y las aceitunas que no recibieron este tratamiento.

Asimismo la salmuera de las aceitunas fermentadas, fue diluida, para evitar que el alto valor porcentual de $\mathrm{NaCl}$, afecte al panelista

\section{Formato para evaluación sensorial}

Indique con un visto, cual muestra le es más agradable, según formato de calificación.

Muestra A:

Muestra B:

Observaciones:

\section{4) Metodología}

El proyecto se desarrolló por la metodología que se observa en la Figura 1: aceitunas fermentadas con acetificación inicial de salmuera aceitunas fermentadas sin acetificación inicial de salmuera, evaluación sensorial de las aceitunas fermentadas, resultados y conclusiones.

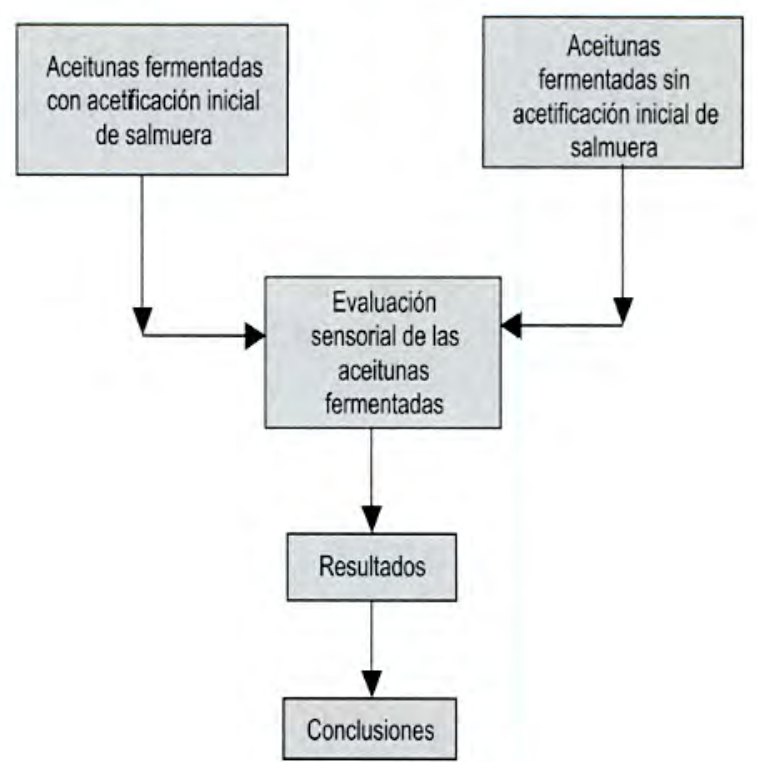

Figura $\mathrm{N}^{0}$ 01: Metodologia de la investigación

\section{5) Procedimiento}

Los procedimientos se desarrollaron para 3 aspectos: para el proceso, para el diseño experimental y para la evaluación sensorial.

- Para el proceso: Consistió en la preparación de las aceitunas negras utilizando salmueras acetificadas y no acetificadas, las cuales se evaluaron sensorialmente una vez concluido el procesamiento.

- Para el diseño experimental: Se realizaron 2 tratamientos con 8 repeticiones cada uno. Cada repetición se evaluó sensorialmente mediante la prueba de comparación por pares. Sometiéndose estos resultados al análisis de varianza.

\section{RESULTADOS}

\section{1) En el Procesamiento}

El cuadro 1, permite observar las características de proceso de fermentación de las aceitunas negras en cuanto a pH, acidez, porcentaje de $\mathrm{NaCl}$ desde el inicio hasta el final de la fermentación.

Cuadro $N^{\circ}$ 01: Control de fermentación de las Aceitunas

\begin{tabular}{|c|c|c|c|c|c|c|}
\hline \multirow{2}{*}{$\begin{array}{c}\text { Tiempo } \\
\text { (dias) }\end{array}$} & \multicolumn{3}{|c|}{$\begin{array}{c}\text { Con acetificación de } \\
\text { salmuera }\end{array}$} & \multicolumn{3}{c|}{$\begin{array}{c}\text { Sin acetificación de } \\
\text { salmuera }\end{array}$} \\
\cline { 2 - 7 } & $\mathrm{pH}$ & Acidez & {$[\mathrm{NaCl} \%]$} & $\mathrm{pH}$ & Acidez & {$[\mathrm{NaCl} \%]$} \\
\hline Inicio & 3,8 & 0,089 & 10 & 7,6 & 0,0 & 10 \\
10 & 4,5 & 0,12 & 9 & 5,3 & 0,055 & 9 \\
30 & 4,85 & 0,19 & 9,5 & 5,0 & 0,26 & 9,5 \\
60 & 4,5 & 0,28 & 9,25 & 4,7 & 0,42 & 9,25 \\
90 & 3,1 & 0,62 & 9,25 & 3,75 & 0,52 & 9,25 \\
\hline
\end{tabular}




\section{2) Acondicionamiento de las Aceitunas Fermentadas}

Para la degustación de los panelistas se prepararon concentraciones de sal de 2,5; 5, y 7,5\% de $\mathrm{NaCl}$, ya que al degustar los panelistas las muestras de aceitunas fermentadas, previo a la evaluación, todos observaron el alto contenido de sal de las aceitunas fermentadas.

De los 3 niveles de sal a los que se acondicionó las aceitunas, fue de preferencia de los panelistas las aceitunas acondicionadas a $2,5 \%$ de sal y en segundo lugar las aceitunas con $5 \%$, por lo que se opta para el reporte de los resultados hacer referencia al de las aceitunas acondicionadas a 2,5\%.

\section{3) Evaluación Sensorial de las Aceitunas Negras Fermentadas}

Los cuadro 2 y 3 permiten observar los resultados de la evaluación sensorial para el color y olor y para el sabor y textura respectivamente.

Los resultados de la evaluación sensorial del color de las aceitunas mostraron claramente la diferencia de calidad de las aceitunas negras cuando son fermentadas sin acetificación inicial y con acetificación inicial.

Las aceitunas fermentadas sin acetificación inicial presentaron en todas las muestras, excepto una, el olor normal de las aceitunas fermentadas.

Sin embargo, las aceitunas con acetificación solamente 2 muestras presentaron olor normal y las restantes olor a acético.

Todas las muestras sin acetificación presentaron sabor ácido, mientras que las muestras acetificadas, dos presentaron sabor amargo y una sabor dulce. La textura de las aceitunas en las muestras sin acetificación no presenta variación, mientras que en las muestras acetificadas registra 3 muestras con cambios enla textura.

Cuadro $\mathrm{N}^{\circ} 02$ : Evaluación sensorial para el colory olor

\begin{tabular}{|c|c|c|c|c|}
\hline \multirow{2}{*}{ Muestra } & \multicolumn{2}{|c|}{ COLOR } & \multicolumn{2}{c|}{ OLOR } \\
\cline { 2 - 5 } & $\begin{array}{c}\text { Sin } \\
\text { acetificación }\end{array}$ & $\begin{array}{c}\text { Con } \\
\text { acetificación }\end{array}$ & $\begin{array}{c}\text { Sin } \\
\text { acetificación }\end{array}$ & $\begin{array}{c}\text { Con } \\
\text { acetificación }\end{array}$ \\
\hline 1 & Rojo violeta & Negro violáceo & Normal & Acético \\
\hline 2 & Rojo violeta & Negro violáceo & Normal & Acético \\
\hline 3 & Rojo violeta & Negro violáceo & Normal & Acético \\
\hline 4 & Rojo violeta & Negro violáceo & Acético & Acético? \\
\hline 5 & Rojo violeta & Negro violáceo & Normal & Acético \\
\hline 6 & Rojo violeta & Negro violáceo & Normal & Normal \\
\hline 7 & Rojo violeta & Negro violáceo & Normal & Acético \\
\hline 8 & Rojo violeta & Negro violáceo & Normal & Normal \\
\hline
\end{tabular}

Cuadro $\mathbf{N}^{\circ}$ 03: Evaluación sensorial para el sabor y textura

\begin{tabular}{|c|c|c|c|c|}
\hline \multirow{2}{*}{ Muestra } & \multicolumn{2}{|c|}{ SABOR } & \multicolumn{2}{c|}{ TEXTURA } \\
\cline { 2 - 5 } & $\begin{array}{c}\text { Sin } \\
\text { acetificación }\end{array}$ & $\begin{array}{c}\text { Con } \\
\text { acetificación }\end{array}$ & $\begin{array}{c}\text { Sin } \\
\text { acetificación }\end{array}$ & $\begin{array}{c}\text { Con } \\
\text { acetificación }\end{array}$ \\
\hline 1 & Acido & Acido & Normal & Normal \\
\hline 2 & Acido & Acido & Normal & Normal \\
\hline 3 & Acido & Amargo & Normal & Blando \\
\hline 4 & Acido & Amargo & Normal & Blando \\
\hline 5 & Acido? & Acido & Normal & Normal \\
\hline 6 & Acido & Acido & Normal & Normal \\
\hline 7 & Acido & Dulce & Normal & Normal \\
\hline 8 & Acido & Acido & Normal & Blando \\
\hline & & & & \\
\hline
\end{tabular}

En lo referido al aspecto general de las aceitunas negras fermentadas, en las aceitunas fermentadas sin acetificación de la salmuera solamente una muestra fue calificada como indiferente, todas las restantes fueron del gusto de los panelistas, mientras que las aceitunas fermentadas con acetificación de la salmuera solamente una muestra fue calificada como del gusto del panelista, siendo las restantes calificadas como indiferentes para el gusto de panelistas y otras de disgusto para los panelistas.

Cuadro $N^{\circ}$ 04: Evaluación sensorial para el aspecto general

\begin{tabular}{|c|c|c|}
\hline \multirow{2}{*}{ Muestra } & \multicolumn{2}{|c|}{ ASPECTO GENERAL } \\
\cline { 2 - 3 } & $\begin{array}{c}\text { Sin } \\
\text { acetificación }\end{array}$ & $\begin{array}{c}\text { Con } \\
\text { acetificación }\end{array}$ \\
\hline 1 & Me gusta & Indiferente \\
\hline 2 & Me gusta & Indiferente \\
\hline 3 & Me gusta & Me disgusta \\
\hline 4 & Me gusta & Me disgusta \\
\hline 5 & Indiferente & Indiferente \\
\hline 6 & Indiferente & Indiferente \\
\hline 7 & Me gusta & Me disgusta \\
\hline 8 & Me gusta & Me gusta \\
\hline
\end{tabular}

\section{4) Análisis Estadístico}

Del análisis estadistico de los resultados, aplicado para el color, olor, sabor, textura y aspecto general, utilizando el método de los datos pareados para las aceitunas fermentadas con acetificación y sin acetificación. se puede deducir que existe diferencia entre los tratamientos de las aceitunas con y sin acetificación de las salmueras.

Esta diferencia entre los tratamientos con acetificación y sin acetificación de las salmueras de las 
aceitunas negras se establece ya que el t calculado es demasiado grande (tiende a infinito), mientras que el t de la tabla, con 7 grados de libertad y $99,9 \%$ de significancia es únicamente de 5,408 .

No fue necesario realizar el ANVA, ya que se demostró estadísticamente que todos los atributos sensoriales son importantes para definir diferencias de calidad sensorial en las aceitunas negras fermentadas, cuando se compara las aceitunas con salmuera inicial acetificada y la sin acetificación. Igualmente acontece con la prueba de Tukey.

\section{CONCLUSIONES}

1. Se demostró que la acetificación de las salmueras de aceitunas negras fermentadas afecta la calidad sensorial del producto.

2. Se determinó estadísticamente, por el método de comparación por pares, que todos los atributos sensoriales confieren diferencia de calidad a las aceitunas fermentadas con acetificación de la salmuera inicial con respecto de las aceitunas fermentadas sin salmuera inicial.

3. Se determinó, de las calificaciones efectuadas por los jueces, que los atributos sensoriales de color y olor son los más representativos para marcar diferencia sensorial entre las aceitunas fermentadas con y sin acetificación en la salmuera inicial.

\section{RECOMENDACIONES}

Se recomienda, evaluar la influencia de utilizar otra alternativa diferente al ácido acético para la acidificación de la salmuera inicial, en las características sensoriales de las aceitunas negras fermentadas.

\section{BIBLIOGRAFÍA}

Análisis sensorial y su aplicación en las aceitunas de mesa y en el aceite de oliva virgen. Centro de Difusión Tecnológica (TDC). Unión Europea. 2004.

Calzada J. (1982). Métodos estadísticos para la investigación. UNAla Molina. Quinta edición Lima Perú.

Espinoza Atencia E. (2003) Evaluación sensorial de los alimentos. Tacna Perú.

Instituto de la grasa y sus derivados. (1985). Biotecnología de la aceituna de mesa. Sevilla España.

Loussert y Browsse (1980). El olivo. Ediciones Mundi Prensa. Madrid España.

Ácido acético.

Http://es.wikipedia.org/wiki/\%C3\%81cido ac\%C3\%A9tico 